\title{
Postures and politics
}





\section{FRANK MacKINNON}

\section{Postures and politics}

Some observations on participatory democracy

University of Toronto Press 
(C) University of Toronto Press 1973

Toronto and Buffalo

Printed in Canada

Reprinted in 2018

ISBN 0-8020-1928-5 (cloth)

ISBN 978-0-8020-6167-6 (paper)

ISBN 0-8020-0266-8 (microfiche)

LC 72-95553 